\title{
Synthesis and characterization of nickel/barium hexa-aluminate composite coatings
}

\author{
DINESH KUMAR* , SAMPADA GURAV, VIKRAM JAYARAM and SANJAY KUMAR BISWAS ${ }^{\dagger}$ \\ Department of Materials Engineering, ${ }^{\dagger}$ Department of Mechanical Engineering, Indian Institute of Science, \\ Bangalore 560 012, India
}

MS received 4 October 2011; revised 18 February 2012

\begin{abstract}
Electrodeposition of nickel/barium hexa-aluminate (Ni/BHA) composite coatings has been carried out from a Watt's bath on mild steel substrate. BHA powders with plate habit were synthesized by solution combustion synthesis followed by heat treatment to ensure complete conversion to the hexa-aluminate phase. Heat treated material was characterized by X-ray diffraction (XRD), scanning electron microscopy (SEM) combined with X-ray analysis. The dispersion behaviour and stability of BHA suspensions with cationic and anionic surfactants at room temperature were studied by dynamic light scattering under different $\mathrm{pH}$. The influence of BHA concentration in the electrolytic bath, deposition temperature, $\mathrm{pH}$, current density and duty cycle on particle incorporation in the coatings were studied and conditions for maximum particle incorporation were established. Coatings with a roughness of about $0.4 \mu \mathrm{m}$ were produced by using this technique. Effect of BHA content on microhardness was also investigated. A reasonably good thickness of the coatings was achieved in a given set of conditions.
\end{abstract}

Keywords. Volume fraction; composite coatings; microstructure; scanning electron microscope; X-ray diffraction.

\section{Introduction}

Electrodeposition is gaining much attention during the past few decades for preparing metal matrix composites (MMCs). Many deposition methods have been utilized, including thermal spray, physical vapour deposition, chemical vapour deposition, and electro co-deposition. Out of these and other available techniques, electro co-deposition is the most sought after method for producing MMCs with several merits, such as low cost, low operating temperature, ease of fabrication and high quality deposits, free from porosity and uncontrolled oxide inclusion. The most important advantage of this process is good adhesion which would play a key role for subsequent studies. This process involves the suspension of inert particles in a conventional plating electrolyte and which are captured in the growing metal layer to form a composite coating. Nickel matrix composites (NMCs) are materials in which the properties of a metallic host material are modified by dispersing different types of refractory oxides, nitrides and carbides including several materials that are used as solid lubricants (SLs) (Allam 1991; Ramesh et al 1991a, b; Surender et al 2004). Out of these materials, SLs are important for the reduction of friction and wear between contacting surfaces in extreme environments such as those encountered in aerospace, tooling, materials-forming, automotive and nuclear-power industries (Corte and Sliney

\footnotetext{
*Author for correspondence (dkumar_2008@yahoo.co.in,
} dkumar@platinum.materials.iisc.ernet.in)
1990; Donnet and Erdemir 2004; Voevodin and Zabinski 2005; Baker et al 2007; Gupta et al 2007; Miyoshi 2007). In such applications, conventional lubricants, such as oils or greases, exhibit volatility or undergo chemical degradation. The low shear strength characteristic of nearly all the SLs occurs only in a very limited range of ambient conditions. For example, graphite and molybdenum disulfide $\left(\mathrm{MoS}_{2}\right)$ are the most widely used SLs at room temperature. Graphite cannot provide lubrication in vacuum or dry environments as it needs condensable vapours (e.g. water) to terminate dangling bonds that are otherwise adhesive in nature. $\mathrm{MoS}_{2}$ oxidizes rather quickly in moist air and acts as an abrasive at room temperature. Both of these mechanically soft materials do not impart lubrication property at high temperatures and are not optimized to resist wear in any environment. These limitations lead to the need for new solid lubricants that possess low wear rates and low coefficients of friction over a wide range of working environment (Corte and Sliney 1990; Gupta et al 2007). Of these, MMCs coatings in which ceramic layered oxides can be co-deposited with any metal are potential candidates for providing lubrication at ambient as well as high temperatures in oxidizing environments. Since these MMC coatings possess excellent tribological and wear resistance properties (Ramesh et al 1991a, b, c, d; Pompei et al 2009), high temperature applicability of these layered oxides could be investigated by incorporating them into the metal matrix composite. Among various metals, nickel which possesses high tensile strength, good toughness and corrosion resistances, is a popular choice as the matrix to disperse both hard and soft reinforcements to improve its wear and 
anti-friction resistance (Lele et al 1989; Ramesh et al 1991a, b, c; Hou et al 2002; Wang and Cheng 2003; Wang et al 2005; Pompei et al 2009). Burzynska et al (2008) reported electrodeposition and heat treatment of nickel/silicon carbide composites and their results suggested two phase transformations in the temperature range $20-700{ }^{\circ} \mathrm{C}$. For annealed samples, $\mathrm{Ni}_{2} \mathrm{Si}$ and $\mathrm{Ni}_{3} \mathrm{Si}_{2}$ phases were identified. Aoudi et al (2009) studied the tribological behaviour of $\mathrm{Mo}_{2} \mathrm{~N} / \mathrm{MoS}_{2} / \mathrm{Ag}$ coatings at room temperature, $350{ }^{\circ} \mathrm{C}$ and $600{ }^{\circ} \mathrm{C}$ against $\mathrm{Si}_{3} \mathrm{~N}_{4}$ balls and found the lowest value of coefficient of friction (cof) at $600{ }^{\circ} \mathrm{C}$. This cof value was attributed to the formation of lubricious silver molybdate phases including $\mathrm{Ag}_{2} \mathrm{Mo}_{4} \mathrm{O}_{13}, \mathrm{Ag}_{2} \mathrm{Mo}_{2} \mathrm{O}_{7}$ and $\mathrm{Ag}_{2} \mathrm{MoO}_{4}$ at the contact surfaces. They claim that the superior performance of all the three compounds is due to their layered structure in which weak bonds may shear or even break easily at high temperature and cause reduction in coefficient of friction. Several other groups (Rethinam et al 2004; Kirchhoff et al 2005; Sun and Li 2007; Xia et al 2007, 2008) are also involved in these types of investigations.

Oxide phases have a natural stability at high temperatures when compared to other reinforcements. Layered oxides in which low shear resistance may be expected include natural clay minerals and structures such as the hexa-aluminates and perovskites. It has been reported that magnetoplumbites containing alkaline-earth or rare-earth cations do not exhibit vaporization problem i.e. metal cation loss during heat treatment. The present work aims to develop a processing protocol for the synthesis of phase pure, plate-like barium hexaaluminate $\left(\mathrm{BaAl}_{12} \mathrm{O}_{19}\right)$ with appropriate layered orientation of the platelets and to incorporate it in a Ni matrix through electrodeposition. Objectives was the achievement of a significant volume fraction of oxide particles in films of the desired thicknesses.

\section{Materials and methods}

All chemicals were received from different commercial suppliers and used without any further purification. The purity of each chemical has been mentioned as: $\mathrm{Ba}\left(\mathrm{NO}_{3}\right)_{2}(99.9 \%)$, $\mathrm{Al}(\mathrm{NO})_{3} \cdot 9 \mathrm{H}_{2} \mathrm{O}(95 \%)$, urea $(99 \%), \mathrm{Ni}\left(\mathrm{SO}_{4}\right)_{2} \cdot 6 \mathrm{H}_{2} \mathrm{O}(98 \%)$, $\mathrm{NiCl}_{2} \cdot 4 \mathrm{H}_{2} \mathrm{O}(97 \%)$, boric acid $(99 \cdot 5 \%)$, SDS $(94 \%)$ and CTAB $(96 \%)$.

BHA was synthesized by combustion synthesis in which reactions were carried out using 1:12 molar ratios of barium to aluminum nitrates. The reactants, barium, aluminum nitrates and urea, were dissolved in a minimum quantity of deionized water in a round bottom glass container using a magnetic stirrer. This solution was placed into a preheated muffle furnace at $500( \pm 5)^{\circ} \mathrm{C}$. At this temperature the solution becomes viscous as water goes out leading to spontaneous combustion of the viscous solution. Evolution of various gases such as oxides of nitrogen and ammonia takes place which lead to the formation of foamy material. XRD analysis of the as-prepared foamy material indicated the presence of BHA, barium mono-aluminate (BMA) and alumina.
In order to get single phase BHA this material was further subjected to heat treatment at $1550{ }^{\circ} \mathrm{C}$. Morphological and micro chemical analysis (EDS) was performed on a high resolution scanning electron microscope (Sirion, FEI Instruments) equipped with a Schottky field emission source.

The dispersion behaviour and stability of BHA suspensions with water, sodium dodecyl sulfate (SDS) as anionic surfactant and cetyltrimethylammonium bromide (CTAB) as cationic surfactant were established by dynamic light scattering (Brookhaven Instruments Corporation, Holtsville, USA) under different $\mathrm{pH}$. $1 \mathrm{mM}$ dispersion of BHA in water was prepared with and without surfactants by adding calculated amount of CTAB (0.0182 g) and SDS (0.0144 g). Before particle size and zeta potential measurements, solutions were ultra-sonicated for $3 \mathrm{~min}$ and then subjected to the measurements. Data for particle size measurement was acquired for 25 min with water, CTAB and SDS. Each data point for zetapotential measurements (calculated Zeta Potential Analyser Software-PALS Analyser software) is an average of five runs. In order to adjust the $\mathrm{pH}, 10 \% \mathrm{HNO}_{3}$ (acidic medium) and $10 \% \mathrm{KOH}$ (basic medium) solutions were used.

In order to find the $\mathrm{pH}$ at which charge density on its surface is zero, the point of zero charge (pzc) value was measured. For this measurement, $20 \mathrm{mg}$ of BHA powder was taken in different twelve vials each containing $10 \mathrm{ml}$ of $1 \mathrm{M}$ $\mathrm{KNO}_{3}$ solution. $\mathrm{pH}$ of each vial was adjusted starting from 1 to 12 at an interval of 1 , with the help of $0 \cdot 1 \mathrm{M} \mathrm{HNO}_{3}$ and $0 \cdot 1 \mathrm{M} \mathrm{KOH}$ solution and then the vials were shaken well and kept for $24 \mathrm{~h}$. After this the $\mathrm{pH}$ of each solution was measured and then initial $\mathrm{pH}$ was plotted against final $\mathrm{pH}$. A line was drawn by joining the points which are almost linear i.e. the points which form a line with lowest slope, and the pzc was determined from the extrapolation of this line to the $y$-axis.

Nickel/BHA coatings were deposited from a nickel Watts bath solution with a volume of $100 \mathrm{ml}$ consisting of BHA, $300 \mathrm{~g} / \mathrm{l} \mathrm{NiSO}{ }_{4} \cdot 6 \mathrm{H}_{2} \mathrm{O}, 45 \mathrm{~g} / 1 \mathrm{NiCl}_{2} \cdot 6 \mathrm{H}_{2} \mathrm{O}, 45 \mathrm{~g} / \mathrm{l} \mathrm{H}_{3} \mathrm{BO}_{3}$ and SDS. The ratio of SDS and BHA was kept constant (which

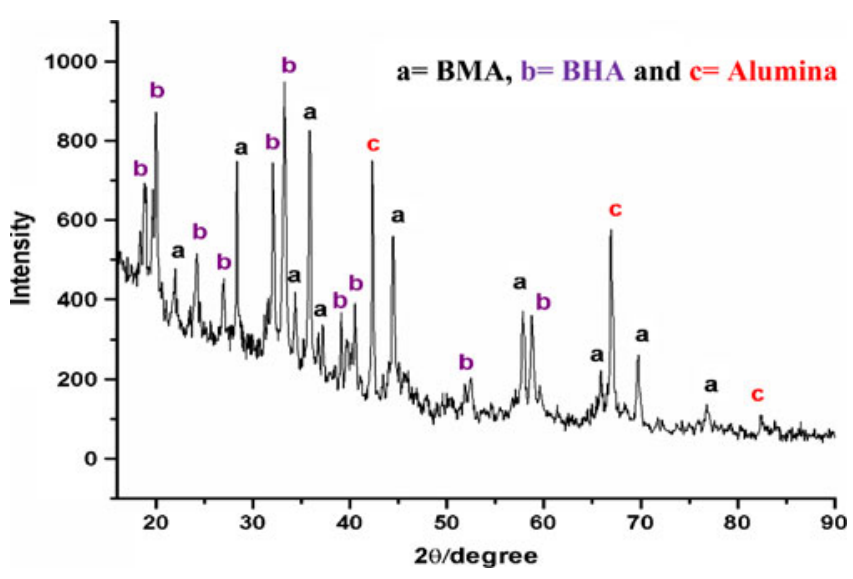

Figure 1. XRD pattern of as synthesized powder containing $\mathrm{BaAl}_{12} \mathrm{O}_{19}$ (BHA), $\mathrm{BaAl}_{2} \mathrm{O}_{4}$ (BMA) and alpha alumina. 


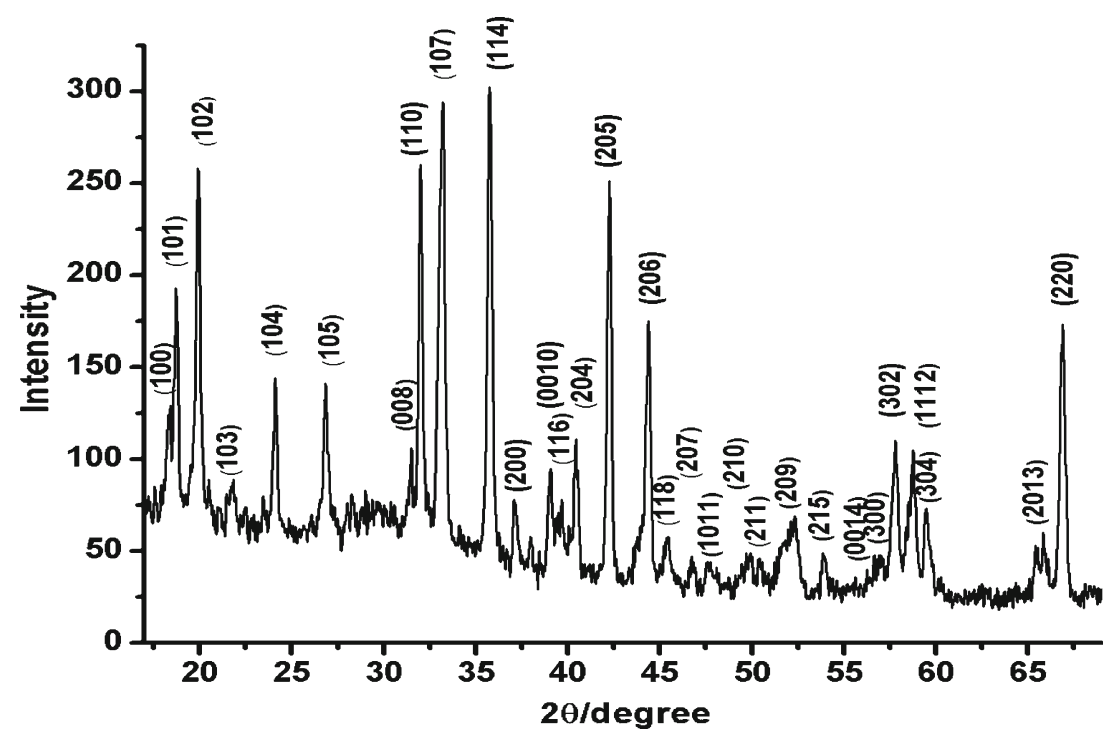

Figure 2. XRD pattern of heat treated oxide powders at $1550{ }^{\circ} \mathrm{C}$ showing single phase BHA.
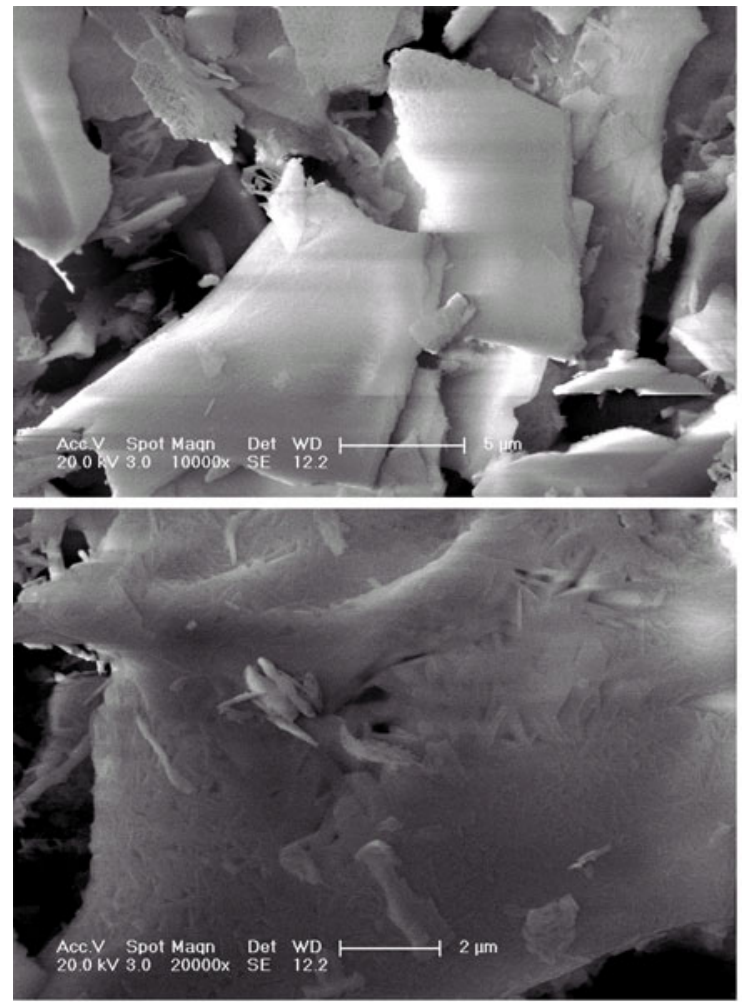

(a)

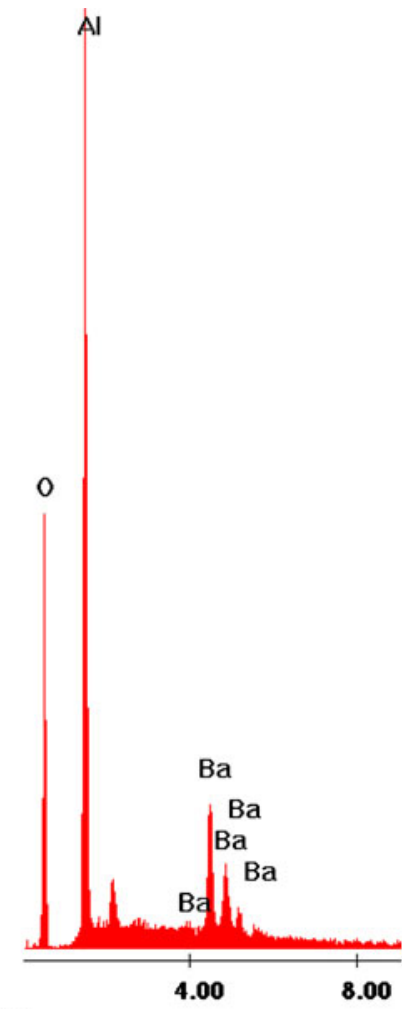

(b)

Figure 3. (a) SEM images showing plate-like morphology of BHA and (b) EDS spectrum showing presence of $\mathrm{Ba}, \mathrm{Al}$ and $\mathrm{O}$ in $\mathrm{BHA}$ powder.

was $1: 100$ by weight) in each and every experiment i.e. as the concentration of BHA increases the amount of SDS increases accordingly. Before adding the BHA into the solution, it was ultra-sonicated for $3 \mathrm{~min}$ and then added to the bath. $\mathrm{pH}$ of the bath was adjusted to 3.0 by adding $\mathrm{H}_{2} \mathrm{SO}_{4}$ and $\mathrm{NH}_{4} \mathrm{OH}$. A rounded double jacketed electrolytic cell with an internal diameter of $5 \mathrm{~cm}$ containing inlet and outlets for flowing hot water from the water bath, was used as an electrodeposition assembly. The temperature of the bath was measured within an error of $\pm 0.5^{\circ} \mathrm{C}$ throughout the experiments. Mild steel plates $(2 \times 1 \times 0.2 \mathrm{~cm})$ were used as cathode and pure nickel plates of purity, $99.9 \%(3 \times 3 \times 0.3 \mathrm{~cm})$ were used as 
anode. Both the cathode and anode were hung vertically with the help of copper wires and separated by a distance of 3.5 $( \pm 0.5) \mathrm{cm}$ in each experiment. Prior to each experiment the mild steel plates were polished on 220, 400,600, 800, 1000, 1200, 1500 and 2000 grit SiC papers and degreased with
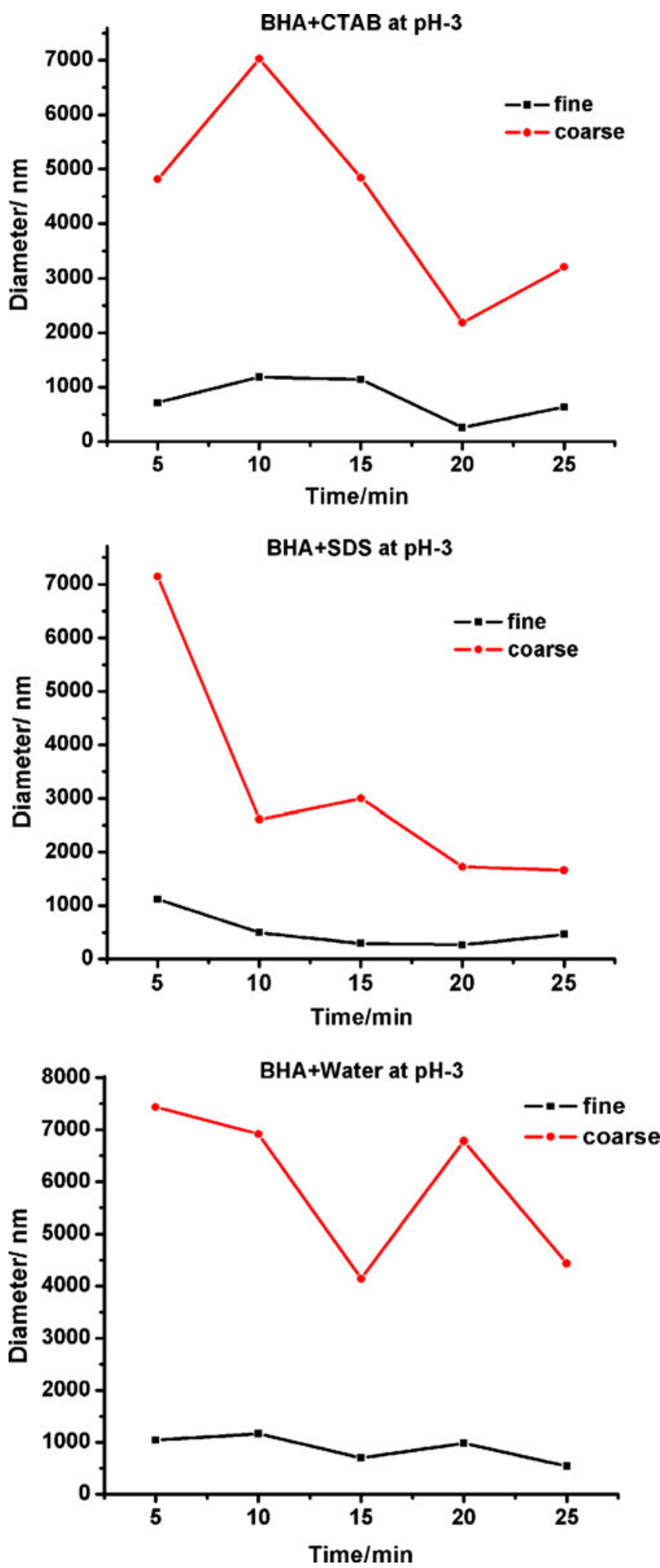

Figure 4. Plot of particle size and time showing bimodal distribution of finer and coarser particles in suspensions.

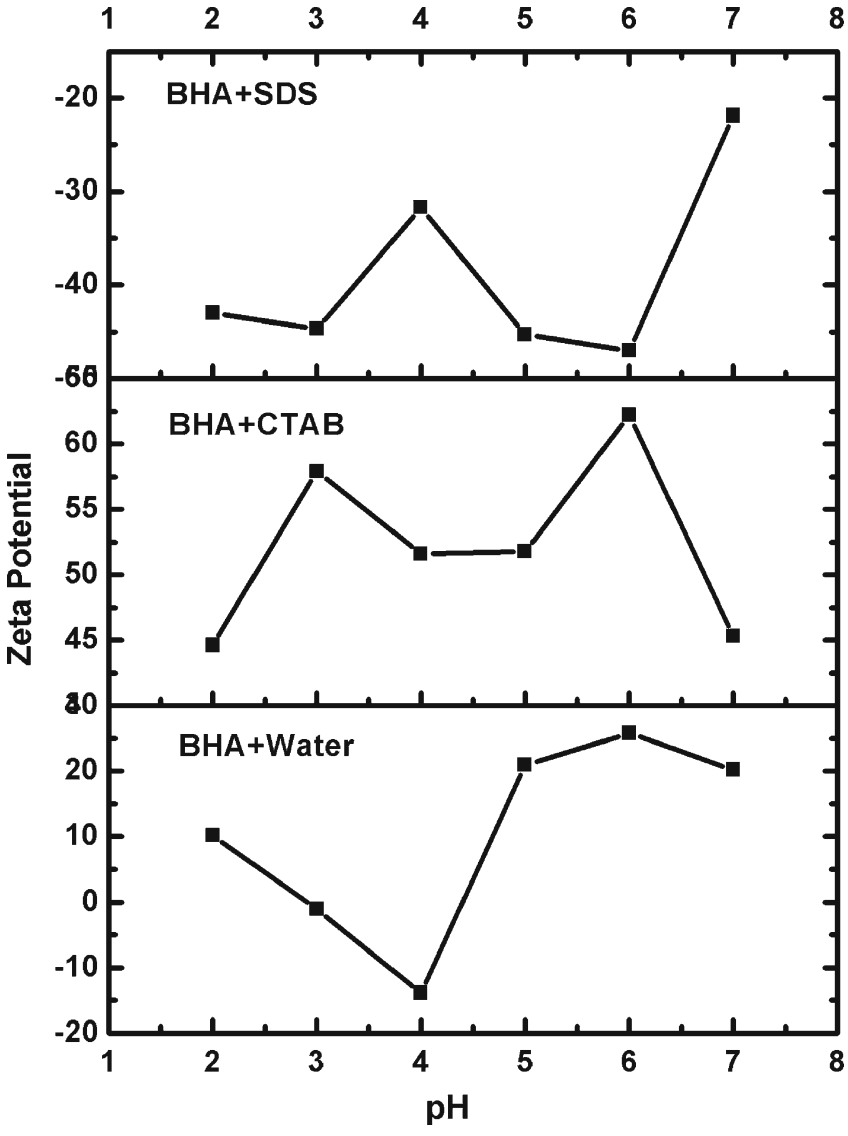

Figure 5. Plot showing variation of zeta potential with $\mathrm{pH}$ for different suspensions.

Table 1. Bath composition and different operating conditions for a fixed deposition time.

$\begin{array}{lc}\mathrm{NiSO}_{4} \cdot 6 \mathrm{H}_{2} \mathrm{O} & 300 \mathrm{~g} / \mathrm{l} \\ \mathrm{NiCl}_{2} \cdot 6 \mathrm{H}_{2} \mathrm{O} & 45 \mathrm{~g} / \mathrm{l} \\ \mathrm{H}_{3} \mathrm{BO}_{3} & 45 \mathrm{~g} / \mathrm{l} \\ \mathrm{Surfactant} & \mathrm{SDS} \\ \mathrm{pH} & 3 \cdot 0( \pm 0 \cdot 05) \\ \text { Temperature }\left({ }^{\circ} \mathrm{C}\right) & 50 \& 60( \pm 0 \cdot 5) \\ \text { Current density }\left(\mathrm{mA} / \mathrm{cm}^{2}\right) & 50 \\ T_{\mathrm{ON}}(\mathrm{ms}) & 2 \\ T_{\mathrm{OFF}}(\mathrm{ms}) & 18 \\ \text { Duty cycle }(\%) & 10 \\ \text { Deposition time (min) } & 60 \\ \text { Stirring (rpm) } & 50-100 \text { (magnetic) }\end{array}$

acetone in a sonicator for $5 \mathrm{~min}$. Electrodeposition was carried out galvanostatically using square-wave pulsed current with current cut-off during the interval between the pulses (Digilog Instruments, Bangalore, India). Different plating parameters such as $\mathrm{pH}$, temperature, current density and duty cycle were varied. The BHA concentration in the bath was varied from 1 to $420 \mathrm{~g} / \mathrm{l}$. During electrodeposition, the suspension was subjected to continuous stirring (50-100 rpm) 
by a magnetic stirrer. All the plating parameters are summarized in tabular form. Deposition time, current densities and duty cycles were fixed in such a way so that a desired thickness of coating could be achieved. After $1 \mathrm{~h}$ plating the coatings were washed with running water and acetone and characterized by XRD (X-Pert PRO, PANanalytical instrument) and SEM. The roughness of the as deposited coatings was measured by 3D Optical Profilometer (WYKO NT100) and average values of roughness were calculated by Vision 32 software. Thickness was measured from cross-sectional view of the coatings by SEM measurements. One fourth of the sample was cut from the bottom and polished with 1200 , 1500 and 2000 grit $\mathrm{SiC}$ papers and then finally with $1 \mu \mathrm{m}$ diamond paste using diamond polishing lubricant on a cloth (supplied from Buehler). After polishing, the samples were

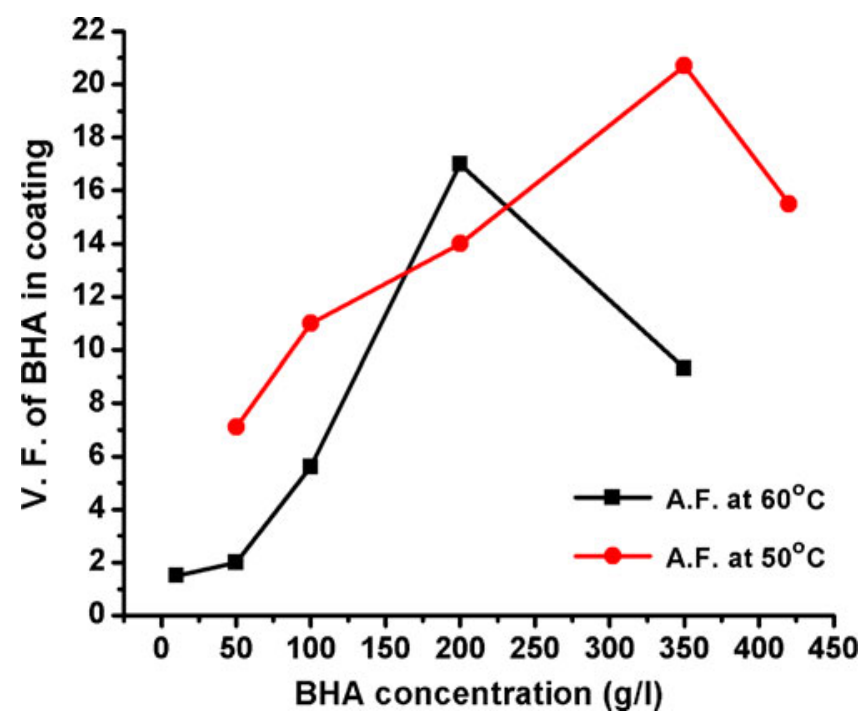

Figure 6. Plot between volume (area) fraction of BHA in coatings and BHA concentration $(\mathrm{g} / \mathrm{l})$ in plating bath. cleaned properly in acetone and desiccated before SEM imaging. SEM images were acquired for both microstructural characterizations as well as image analysis measurements and EDS analysis for micro chemical analysis of the phases present. In order to calculate the volume fraction (area fraction) of BHA in the coatings, image analysis measurements on the BSE images of different samples were performed by using Image j 1.42q software (Wayne Rasband, National Institute of Health, USA). Vickers hardness tester (Diamond Indenter, CSM Instrument) was employed to evaluate the microhardness of the coatings (top view) using a load of $1 \mathrm{~N}$. Five measurements were conducted on each sample.

\section{Results and discussion}

\subsection{Synthesis and characterization of BHA}

The powder obtained at $500{ }^{\circ} \mathrm{C}$ by solution combustion synthesis (Das and Patil 1994) (as synthesized powder) contains BHA, BMA and alumina $\left(\mathrm{Al}_{2} \mathrm{O}_{3}\right)$. The following reaction is expected to take place during combustion of the aqueous reaction mixture:

$$
\begin{aligned}
& \mathrm{Ba}(\mathrm{NO})_{3}+12 \mathrm{Al}\left(\mathrm{NO}_{3}\right)_{3} \cdot 9 \mathrm{H}_{2} \mathrm{O}+x \mathrm{CH}_{4} \mathrm{~N}_{2} \mathrm{O}+y \mathrm{H}_{2} \mathrm{O} \\
& \stackrel{500{ }^{\circ} \mathrm{C}}{\mathrm{BHA}} \mathrm{BaAl}_{12} \mathrm{O}_{19}+\text { volatile species. }
\end{aligned}
$$

From the above reaction we can conclude that its incompleteness leads to free $\mathrm{BaAl}_{2} \mathrm{O}_{4}\left(\mathrm{BaO} \cdot \mathrm{Al}_{2} \mathrm{O}_{3}\right)$ and $\mathrm{Al}_{2} \mathrm{O}_{3}$ which is obvious from the XRD pattern of as-synthesized powder (figure 1). From XRD pattern we can clearly see two maximum intensity peaks, one at $2 \theta=35.6$ corresponding to (114) which is the maximum intensity peak for BHA and $2 \theta=28.3$ which is the maximum intensity peak for BMA corresponding to (202) peak. The peaks for alumina

Table 2. Thickness, volume fraction of BHA in coatings and roughness of coatings at $\mathrm{pH} 3.0( \pm 0.05)$ for $1 \mathrm{~h}$

\begin{tabular}{|c|c|c|c|c|}
\hline Sl. no. & $\begin{array}{l}\text { BHA conc. } \\
\text { in bath }(\mathrm{g} / \mathrm{l})\end{array}$ & $\begin{array}{l}\text { Volume fraction of } \\
\text { BHA in coating }\end{array}$ & $\begin{array}{l}\text { Thickness } \\
(\mu \mathrm{m})\end{array}$ & $\begin{array}{c}\text { Surface roughness of as } \\
\text { deposited sample(nm) }\end{array}$ \\
\hline \multicolumn{5}{|c|}{ Electrodeposition at $60 \pm 0.5^{\circ} \mathrm{C}$} \\
\hline 1 & 10 & 1.5 & 80 & 600 \\
\hline 2 & 50 & $2 \cdot 0$ & 70 & 380 \\
\hline 3 & 100 & $5 \cdot 6$ & 50 & 335 \\
\hline 4 & 200 & 17 & 60 & 375 \\
\hline 5 & 350 & $9 \cdot 3$ & 85 & 495 \\
\hline \multicolumn{5}{|c|}{ Electrodeposition at $50 \pm 0.5^{\circ} \mathrm{C}$} \\
\hline 6 & 50 & $7 \cdot 1$ & - & 545 \\
\hline 7 & 100 & 11 & 8 & 190 \\
\hline 8 & 200 & 14 & 8 & 175 \\
\hline 9 & 300 & $14 \cdot 3$ & 8 & 200 \\
\hline 10 & 350 & $20 \cdot 7$ & 11 & 120 \\
\hline 11 & 420 & $15 \cdot 5$ & 5 & 235 \\
\hline
\end{tabular}
deposition and $50 \mathrm{~mA} / \mathrm{cm}^{2}$ current density. 
are at $2 \theta=42.3,66.9$ and 82.4 which correspond to (202), (330) and (402) peaks, respectively. Single phase BHA was obtained when this powder was subjected to heat treatment at $1550{ }^{\circ} \mathrm{C}$ (heating rate, $10{ }^{\circ} \mathrm{C} / \mathrm{min}$ ) for $6 \mathrm{~h}$ (figure 2 ) which could be inferred by the disappearance in the intensity of peak at 28.3. It has been reported that for powder mixtures, BHA is formed through solid state reaction between $\mathrm{BaO} \cdot \mathrm{Al}_{2} \mathrm{O}_{3}$ and alumina by diffusion (Machida et al 1988). Davies et al (1998) also mentioned that BMA is formed as an intermediate phase, with little densification and converts to BHA with densification from mixture of alumina and barium carbonate powders.

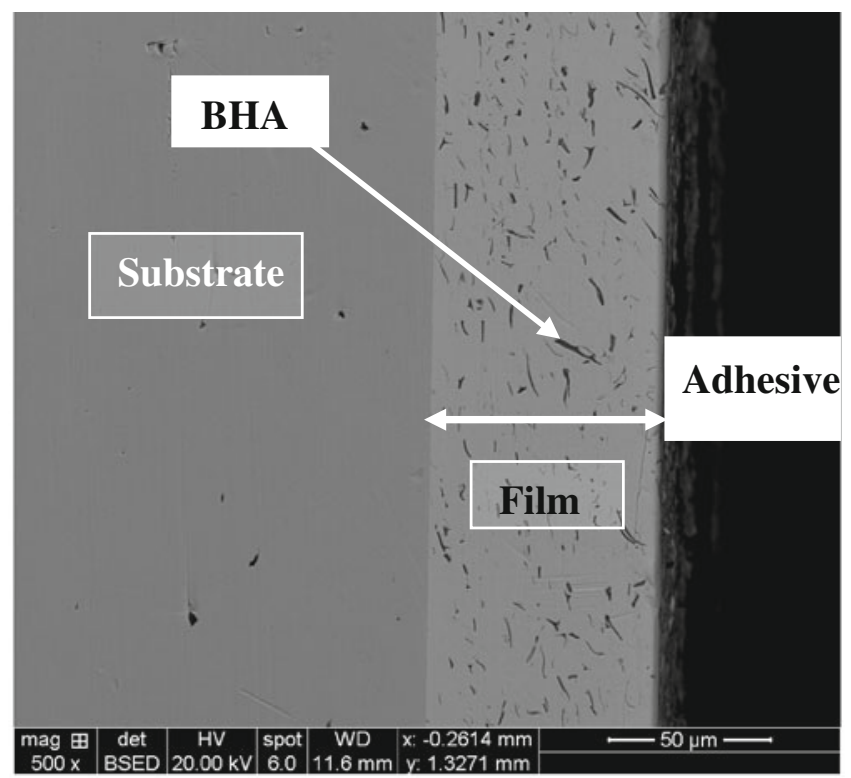

(a)

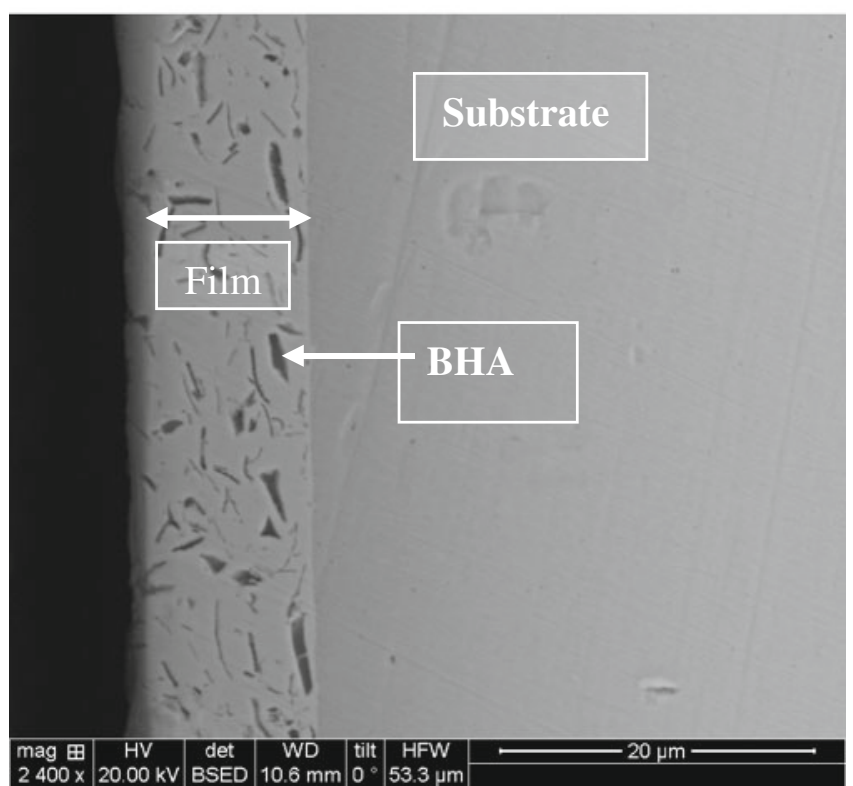

(b)

Figure 7. Cross-sectional view (SEM) of composite coating deposited at 50 and $60{ }^{\circ} \mathrm{C}$.
SEM examination of BHA powders (figure 3(a)) reveals its layered structure and plate-like morphology in which each plate is located above the other and so on. Since the lattice is hexagonal, the 001 basal planes correspond to the plate habit (Debsikdar 1989). Microanalysis of all the elements present was confirmed by EDS analysis (figure 3(b)). This layered structure of the mixed oxide has magnetoplumbite $\left(\mathrm{Pb}^{2+} \mathrm{Fe}_{12} \mathrm{O}_{19}\right)$ structure which in the present case consists of layered spinel blocks of $\left(\mathrm{Al}_{11} \mathrm{O}_{16}\right)^{+}$with $\mathrm{Ba}^{2+}$ cation (Utsonomiya et al 1988).

\subsection{Dispersion behaviour and stability of different suspensions}

Particle size analysis of different suspensions with water, SDS and CTAB by DLS shows a bimodal distribution curve (figure 4) indicating that the suspensions contain both fine as well as coarse particles. On the basis of these observations, it could be inferred that the dispersion of BHA particles in SDS at $\mathrm{pH} 3$ is reasonably homogeneous. The magnitude of zeta potential of the particle is a measure of this particle interaction, which provides an indication of the long term stability of a suspension. If the particles in a suspension have a large negative or positive zeta potential then they will tend to repel each other and check aggregate formation. On the other hand, if they have low or close to 0 zeta potential values then particles are free to attract through van der Waals forces and aggregate. Conventionally, the border line of zeta potential for any suspension to be stable is $\pm 30 \mathrm{mV}$ (Malvern Instruments 2005). Figure 5 shows the zeta potential values of different suspensions at various $\mathrm{pH}$. It can be concluded that zeta potential values are higher with CTAB at all $\mathrm{pH}$ than with water or SDS. Point of zero charge for BHA was determined to be 6.6 above which the surface is positively charged and below which it is negatively charged. Thus, codeposition of BHA in acidic media will require anionic surfactants and for basic condition cationic surfactants in order to carry particles towards cathode.

\subsection{Electrodeposition with different operating conditions}

The key parameters for the pulsed electrodeposition of any metal/metal ceramic composites are temperature, $\mathrm{pH}, \mathrm{cu}-$ rrent, and particle/ceramic concentration in the bath (table 1). There are other parameters such as the duty cycle (on and off times) which play a vital role in the quality and adherence of these composite coatings. In addition, bath composition, deposition time and agitation speed also play important roles.

The first key deposition parameter is temperature. The electrodeposition of nickel composites has been extensively performed at temperatures of $30-60{ }^{\circ} \mathrm{C}$ (Rethinam et al 2004), $40{ }^{\circ} \mathrm{C}$ (Wang et al 2005), $50{ }^{\circ} \mathrm{C}$ (Hou et al 2002; $\mathrm{Qu}$ et al 2003; Lee et al 2007; Pompei et al 2009), $60{ }^{\circ} \mathrm{C}$ (El-Sherik et al 1996; Webb and Roberstson 1994; Parida 
et al 2011) and $65{ }^{\circ} \mathrm{C}$ (Chaparro et al 2007). In the present work, we have confined our attention to 2 temperatures of 50 and $60{ }^{\circ} \mathrm{C}$. It has been found that the volume fraction (VF) of BHA in the coatings deposited at $50{ }^{\circ} \mathrm{C}$ was maximum for lower BHA concentration as compared to $60{ }^{\circ} \mathrm{C}$ for a given same set of parameters such as bath composition, current density, duty cycle and $\mathrm{pH}$ (figure 6). Another interesting result is that only $10{ }^{\circ} \mathrm{C}$ difference in temperature leads to a considerable effect on the thickness of the coating (i.e. the deposition rate) as shown in table 2. The thickness of the coatings deposited at $60{ }^{\circ} \mathrm{C}$ was about $60 \mu \mathrm{m}$, which is much higher than $8 \mu \mathrm{m}$ formed at $50^{\circ} \mathrm{C}$, with other parameters constant as shown in figures 7(a) and (b). This is possibly due to the decrease in the rate of diffusion of the nickel ions with temperature (Hamid and Ghayad 2002). While deposition at $50{ }^{\circ} \mathrm{C}$ leads to the maximum incorporation of $\mathrm{BHA}$,
$60{ }^{\circ} \mathrm{C}$ is also suitable if a higher rate of deposition is required. While the thickness at $50{ }^{\circ} \mathrm{C}$ could also be increased by increasing deposition time, $\mathrm{pH}$ of the Watts bath tends to drift to higher values and requires constant adjustment if times much longer than an hour are involved.

The second key parameter to be considered is $\mathrm{pH}$. It may be noted that while the electrolyte composition is different from that of the bath used for zeta potential measurements, there appears to be some consistency in the 2 sets of results. From figure 5, we see that the zeta potential value for $\mathrm{BHA}+\mathrm{SDS}$ suspension at $\mathrm{pH} 3$ was $-44.7 \mathrm{mV}$ which assures a degree of colloidal stability. Thus, electrodeposition at $\mathrm{pH} 3$, as was actually performed, appears to be an acceptable compromise. In the present work, our contention is that, in order to facilitate greater incorporation of BHA in the coating, the rate of nickel deposition should be comparatively

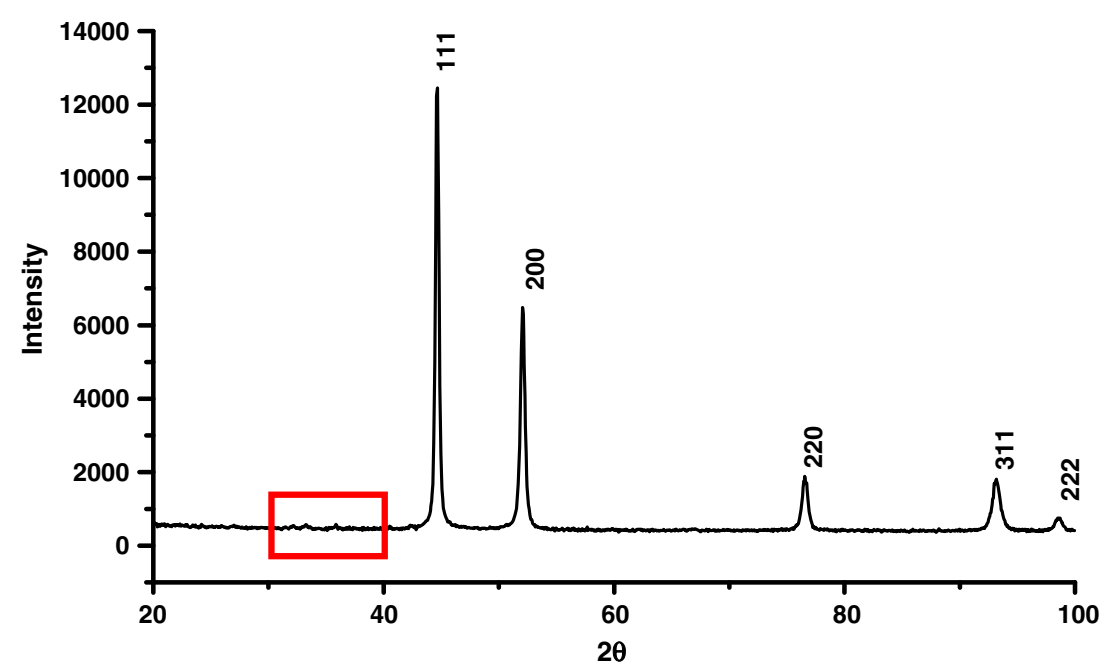

(a)

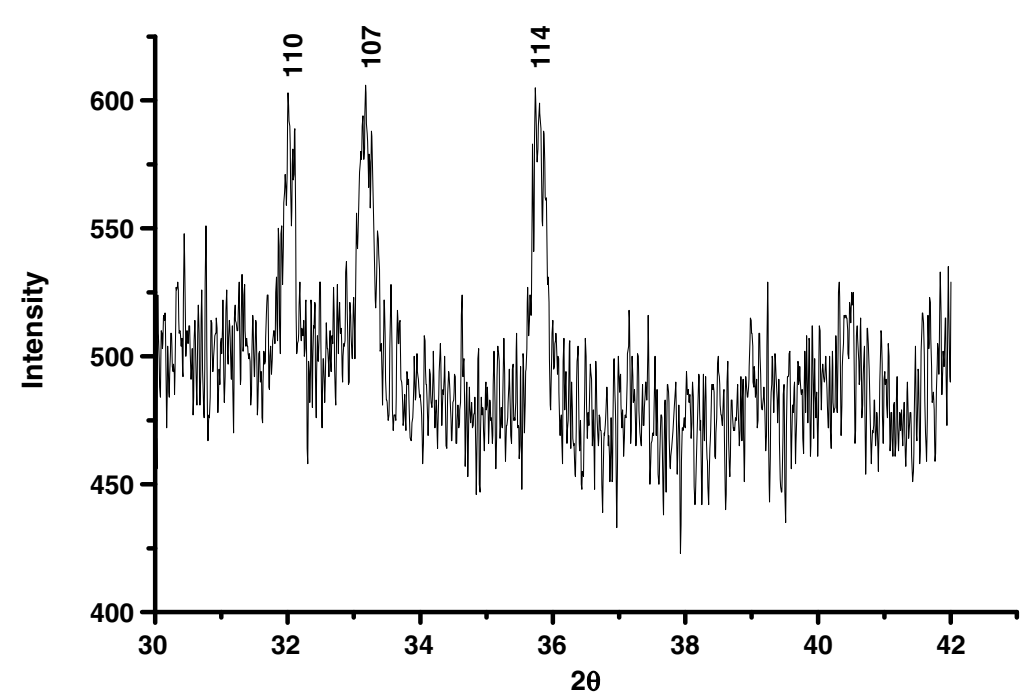

(b)

Figure 8. (a) XRD pattern of Ni/BHA composite coating with $200 \mathrm{~g} / \mathrm{l}$ BHA (full scan) and (b) XRD pattern between $2 \theta=30-42^{\circ}$ (marked in red region in figure 8a) and theoretical maximum intensity peak is 114 . 


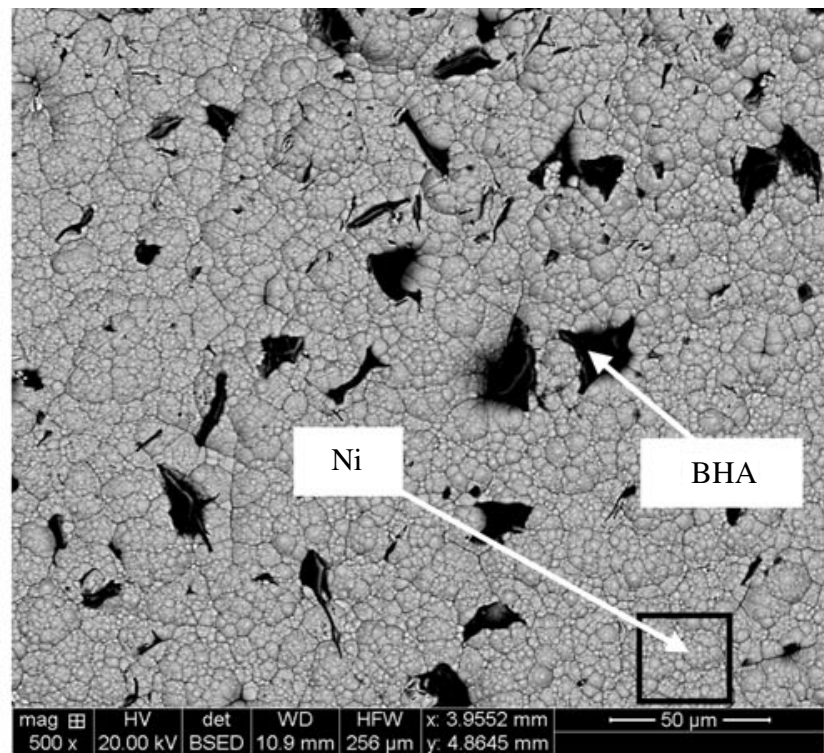

(a)

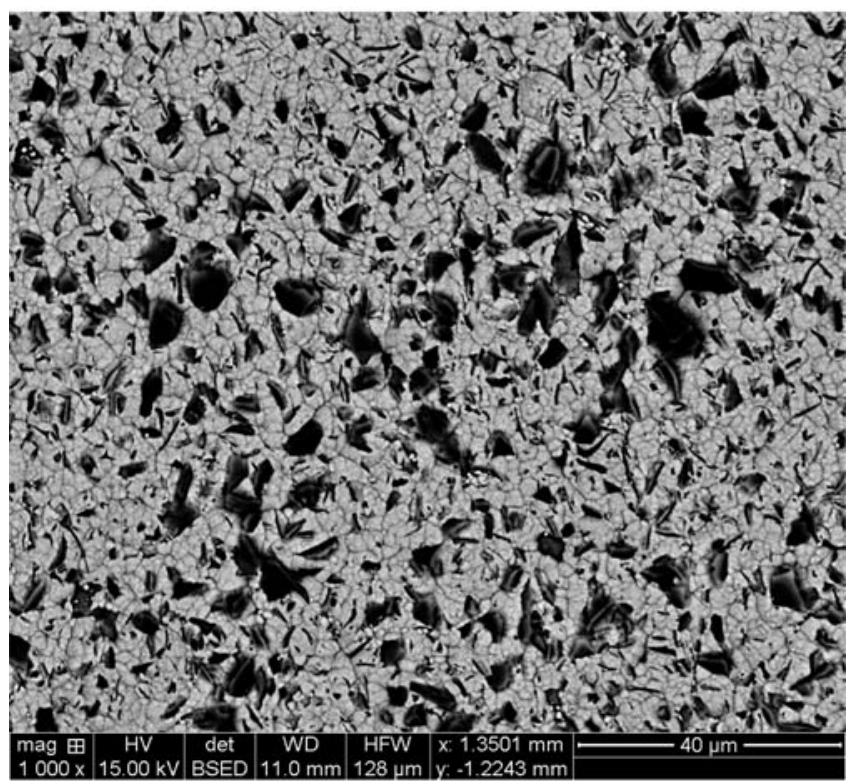

(b)

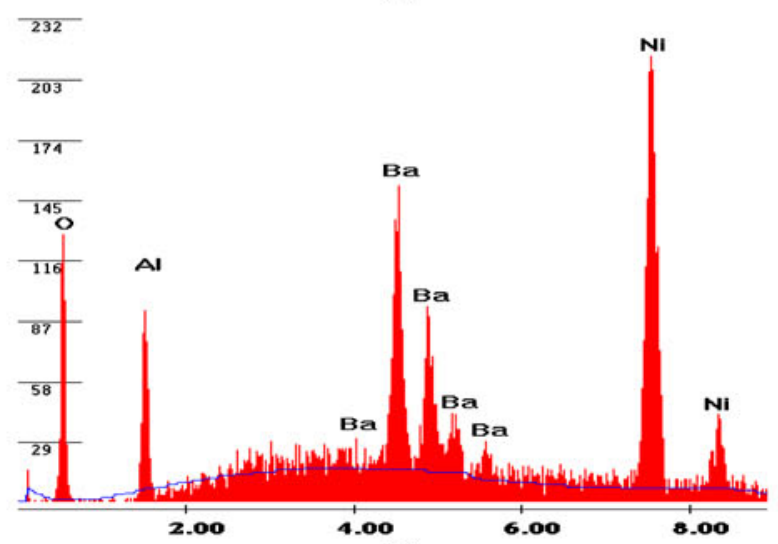

(c)

Figure 9. SEM images of composite coating deposited at $60^{\circ} \mathrm{C}$ with BHA suspension concentrations of (a) $10 \mathrm{~g} / \mathrm{l}$ and (b) $200 \mathrm{~g} / \mathrm{l}$. (c) EDS spectra from dark (BHA) phase of as-deposited coating. lower. So here we have worked with $50 \mathrm{~mA} / \mathrm{cm}^{2}$ peak current density in all the cases (table 1).

\subsection{X-ray characterization and surface morphologies of as deposited coatings}

From the XRD pattern of the coatings (figure 8(a)), we can see the characterstics peak for crystalline nickel only. Peaks for BHA are not clear in this XRD pattern. In order to trace the BHA peaks, XRD measurements have been carried out between different intervals of $2 \theta$ values. Only three peaks for BHA at $2 \theta=32 \cdot 0,33 \cdot 1$ and 35.6 have been observed (figure $8(\mathrm{~b})$ ). These peaks correspond to (110), (107) and (114) plane, out of which (114) peak is the maximum intensity peak. Since Ni is the majority phase and has a higher scattering factor, its peak intensities are much higher than those of BHA. Hence, only BHA peaks with high relative intensites are detected in the XRD pattern. It has also been observed that for the coatings in which volume fraction of BHA was less than $\sim 5$, these peaks could not be detected. However, surface morphologies of as-deposited composite coatings shown in figures 9(a) and (b), clearly show that these particles are embedded in the nickel matrix. EDS spectrum shown in figure 9(c) confirms the presence of BHA particles in the coatings. It is also obvious that the $\mathrm{Ni}$ grain size is almost homogeneous in the coatings (about 2-4 $\mu \mathrm{m}$ ). The roughness of these coatings (table 2$)$ is $300( \pm 150) \mathrm{nm}$; indicative of the fact that deposition of $\mathrm{Ni}$ is homogeneous and that the particles are not agglomerated.

\subsection{Microstructural studies}

Figure 10 shows SEM micrographs of the top-view of Ni/BHA composite coatings after metallographic polishing. Comparison of figures 10(a) and (b) reveal the significant increase in BHA volume fraction when the dispersion loading in the bath is increased from $10 \mathrm{~g} / \mathrm{l}$ to $200 \mathrm{~g} / \mathrm{l}$. However, the trend in particulate loading is nonlinear and displays a maximum with dispersion concentration (figure 6) which changes from $17 \%$ at $200 \mathrm{~g} / \mathrm{l}\left(\right.$ at $60{ }^{\circ} \mathrm{C}$ ) to $\sim 21 \%$ at $350 \mathrm{~g} / \mathrm{l}$ (at $50{ }^{\circ} \mathrm{C}$ ). Another pronounced difference observed between these two temperatures is the large difference in thickness (nearly an order of magnitude). Hence, from figure 6, three points emerge: (i) particulate loading in the film does not increase linearly with suspension concentration; indeed, a reversal takes place, i.e. volume fraction of BHA in the coating decreases beyond a critical bath concentration, (ii) the above nonlinearity and maximum value are different at the two temperatures and (iii) the volume fraction of BHA in the film is greater at $50{ }^{\circ} \mathrm{C}$ than at $60^{\circ} \mathrm{C}$.

Nonlinearity has been reported earlier (Muller et al 2002; Shi et al 2006) but without clear explanations. Here we have assumed that for a fixed area of the matrix, a limited number of particles can be accommodated. If we allow these particles to codeposit with the matrix then they will keep 

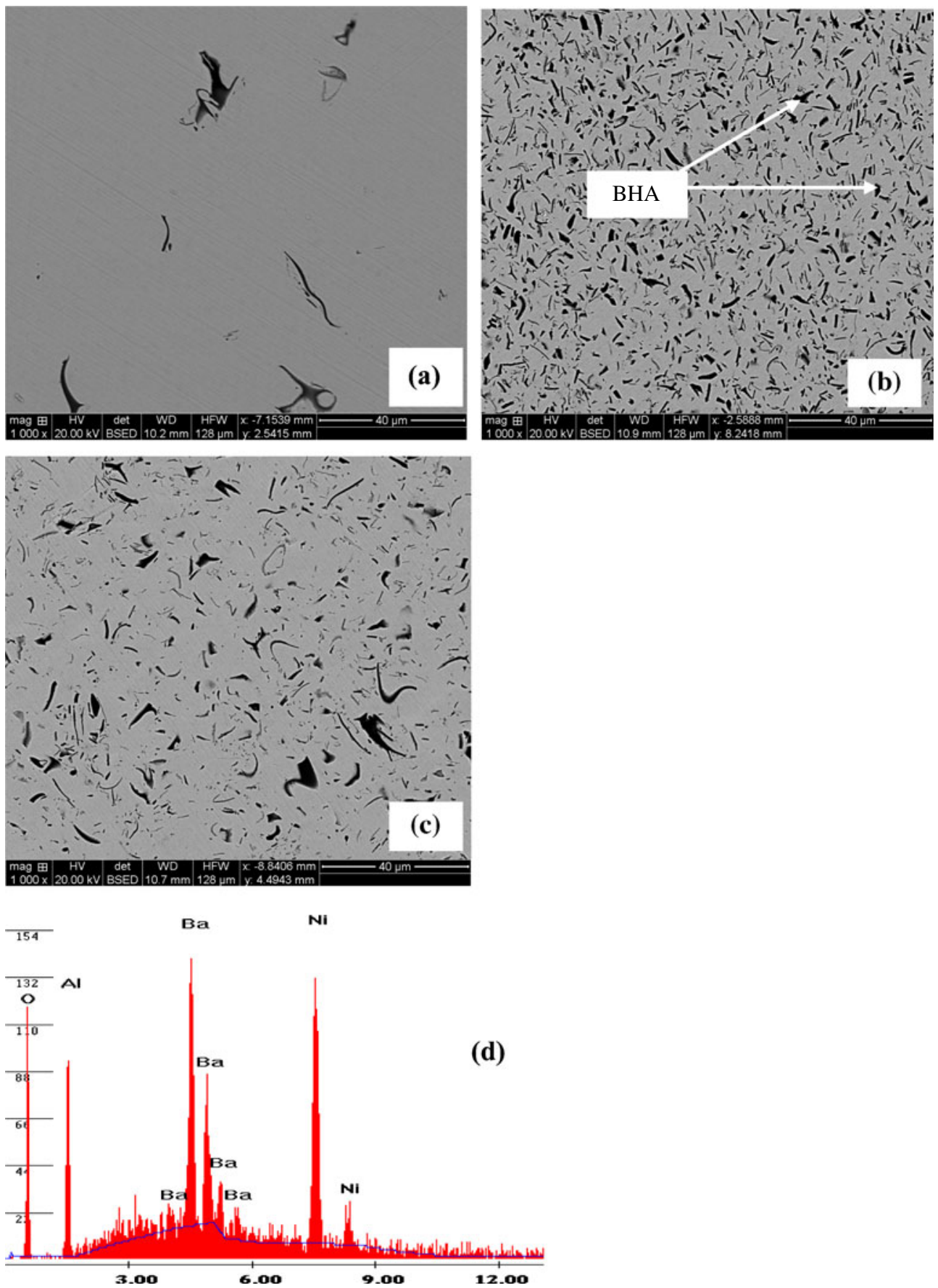

Figure 10. Microstructures (planar view) of polished coatings with (a) 10, (b) 200 and (c) $350 \mathrm{~g} / \mathrm{l}$ of BHA at $60{ }^{\circ} \mathrm{C}$ and (d) EDS spectrum from dark (BHA) region of coatings.

coming unless they have the space to sit on the matrix surface. After a certain concentration of these particles when the distances between these particles reaches the minimum i.e. inter-particle distance reaches minimum, they exhaust the available sites. In other words, we can say that interparticle distance has reached at its minimum value. This is the event which appears to be taking place at higher BHA loadings where volume fraction was found to reach a maximum.

\subsection{Extension of Guglielmi model}

In order to understand second and third points we will explore the Guglielmi (1972) model according to which we can define adsorption coverage $(\sigma)$ in the following way:

$$
\sigma=S_{\mathrm{T}} / S_{\mathrm{P}},
$$

where $S_{\mathrm{T}}$ is the total electrode area and $S_{\mathrm{P}}$ the area overshadowed by the adsorbed particles, since, we have two 
temperatures, 50 and $60{ }^{\circ} \mathrm{C}$. At higher temperature, the particles will exert greater thermal agitation or Brownian movement while sitting at the electrode. During this period $S_{\mathrm{P}}$ would increase and cause a lowering of $\sigma$. Thus, the value of $\sigma$ will be higher at $50{ }^{\circ} \mathrm{C}$ than at $60{ }^{\circ} \mathrm{C}$. The other possible explanation lies in the increased movement of ions with temperature which causes increase in kinetic energy of BHA particulates. According to Langmuir theory, increase in temperature leads to the decrease in the absorbability of the particulates and hence to decrease in the overpotential and electric field. Thus it becomes harder for the BHA particulate to become embedded in the matrix and subsequently causes decrease in the area fraction of BHA particles (Chang and Lee 1988). The reason for decreases in thickness due to variation in temperature has already been mentioned in an earlier section.

Microhardness studies showed that the hardness of $\mathrm{Ni} / \mathrm{BHA}$ composite coatings increases as the BHA content increases in coatings (figure 11). Hardness values are measured as $355 \mathrm{HV}$ for coating having $1.5 \%$ volume fraction of BHA and $410 \mathrm{HV}$ for $17 \%$ volume fraction of BHA. Hence it can be inferred that incorporation of BHA particulates has significant effect on hardness values of these coatings.

Interest has also been growing to see the effects of various plating parameters during electrodeposition of various composite coatings (Zoikis-Karathanasis et al 2010;

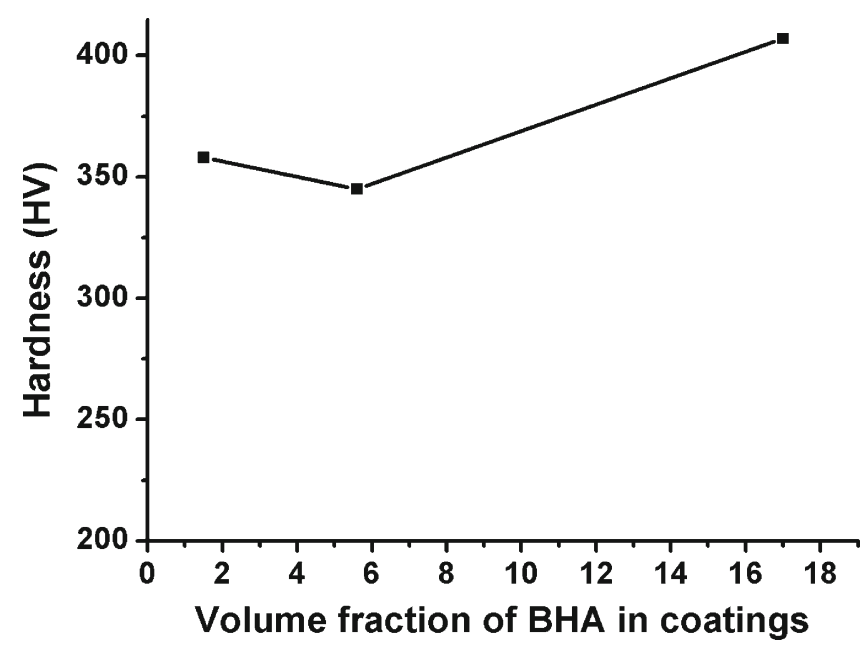

Figure 11. Plot showing variation of microhardness of different coatings with increase in volume fraction of BHA. Scatter in results is $\sim 15 \mathrm{HV}$.

Table 3. Effect of $\mathrm{pH}$ on VF of BHA in coatings, at $200 \mathrm{~g} / \mathrm{l} \mathrm{BHA}$ loading, peak current density $\left(i_{\mathrm{P}}\right) 50 \mathrm{~mA} / \mathrm{cm}^{2}, 60{ }^{\circ} \mathrm{C}$ and $10 \%$ duty cycle.

\begin{tabular}{lcc}
\hline S1. no. & $\mathrm{pH}$ & VF of BHA in coatings \\
\hline 1 & 3.05 & $17 \cdot 0$ \\
2 & 4.03 & $6 \cdot 3$ \\
\hline
\end{tabular}

Sohrabia et al 2010; Choua et al 2005; Borkar and Harimkar 2011). Hence, in addition to these investigations we have also observed the effect of various factors such as $\mathrm{pH}$ (table 3), current density (table 4), and duty cycle (table 5) on volume fraction of BHA in the coatings. Electrodeposition for $200 \mathrm{~g} / \mathrm{l}$ at $\mathrm{pH} 4\left(\right.$ at $60{ }^{\circ} \mathrm{C}$ ) was also performed and results have shown that with the increase in $\mathrm{pH}$ from 3 to 4 , there was a decrease in the volume fraction of BHA (table 3 ). Along with decrease in volume fraction, agglomeration of BHA particles in the coating was also observed (figure 12). Table 1 shows that the zeta potential value for SDS suspension at $\mathrm{pH} 4$ was lower which may decrease the stability of the particles and cause agglomeration. After agglomerate formation the mobility of these particles will reduce and they will not reach to the cathode easily. Influence of peak current density was observed by decreasing current density from 50 to $20 \mathrm{~mA} / \mathrm{cm}^{2}$ (at $60{ }^{\circ} \mathrm{C}$ ). From table 4 , it is obvious that decrease in peak current density results in increase in area fraction. This may be due to the fact that by decreasing the peak current density, the rate of nickel deposition would be slower and during those periods more particles would be able to deposit. Another possible explanation for this observation may be related to the idea that electrochemical potential affects the adsorption of BHA particulates on substrate surface. Thereby, the higher the current density, the lower the cathodic deposition potential, the higher the negative charging of the double layer to repel BHA particulates, and lower the adsorption of BHA (Chang and Lee 1988).

From table 5 we can also see that for the same BHA loading, there was an increase in the volume fraction by decrease in duty cycle. Similar behaviour was also shown by the pulse electrodeposited composite coatings of Ni-P matrix (ZoikisKarathanasis et al 2010). Decrease in duty cycle would naturally cause a decrease in the deposition rate of nickel. At the same time due to an increase in off time, the time experienced by double layer for discharging the negatively charged layer would be higher which would more readily enable the particle to approach the cathode.

Table 4. Effect of peak current density on VF of BHA in coatings at pH $3.0( \pm 0.5), 350 \mathrm{~g} / \mathrm{l}$ loading $\mathrm{BHA}, 60^{\circ} \mathrm{C}$ and $10 \%$ duty cycle.

\begin{tabular}{lcc}
\hline Sl. no & $i_{\mathrm{P}}\left(\mathrm{mA} / \mathrm{cm}^{2}\right)$ & VF of BHA in coatings \\
\hline 1 & 50 & $9 \cdot 3$ \\
2 & 20 & $20 \cdot 8$ \\
\hline
\end{tabular}

Table 5. Effect of duty cycle on VF of BHA in coatings at $\mathrm{pH}$ $3.0( \pm 0 \cdot 5), 350 \mathrm{~g} / 1 \mathrm{BHA}$ loading, $50{ }^{\circ} \mathrm{C}$ and $50 \mathrm{~mA} / \mathrm{cm}^{2}$ current density.

\begin{tabular}{lcc}
\hline Sl. no. & Duty cycle $(\%)$ & VF of BHA in coatings \\
\hline 1 & 10 & $15 \cdot 5$ \\
2 & 5 & $22 \cdot 5$ \\
\hline
\end{tabular}




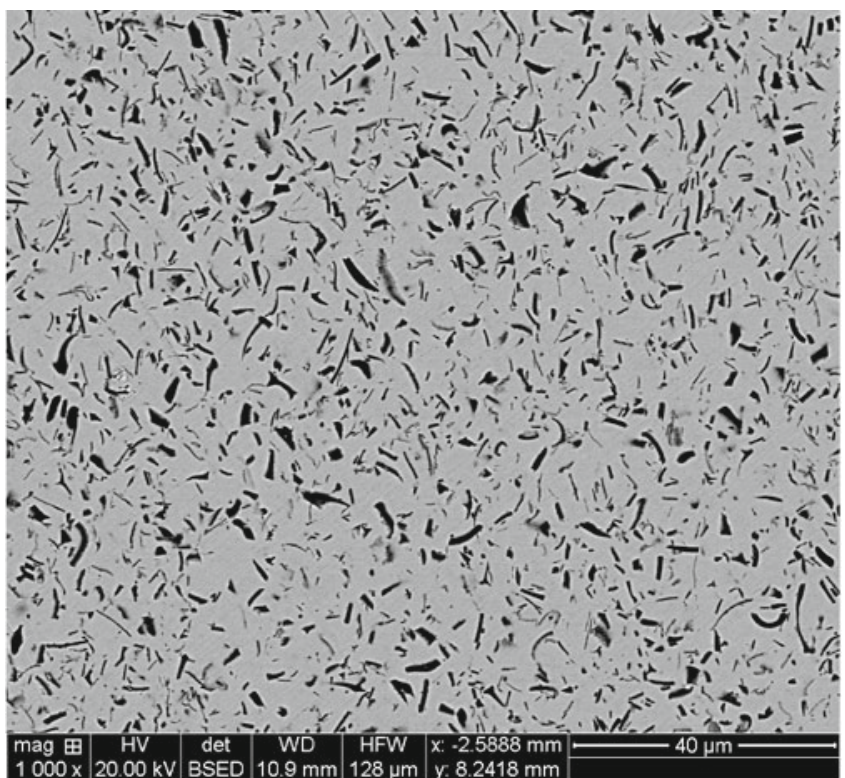

(a) At pH-3

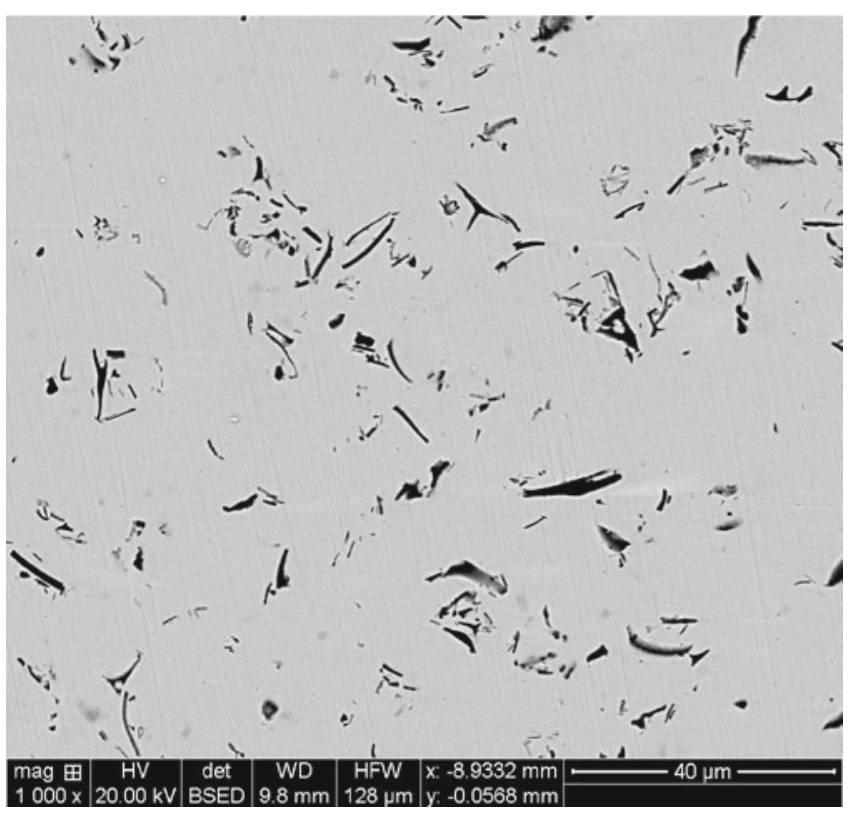

(b) At pH-4

Figure 12. Microstructures showing effect of pH (3 and 4) on volume fraction of BHA measured on planar view of coatings.

\section{Conclusions}

Single phase BHA powder has been synthesized by combustion synthesis with sub-micron particle size and a platelike morphology. The dispersion behaviour and stability of different suspensions with cationic and anionic surfactants have shown that BHA can be stabilized by addition of surfactants and control of $\mathrm{pH}$ and successfully incorporated into the nickel matrix by electrodeposition. The volume fraction of BHA incorporated in the coating displays a maximum with respect to increasing suspension concentration.
BHA was shown to be uniformly distributed in the film with a roughness of $\sim 0.4 \mu \mathrm{m}$. A reduction of deposition temperature from 60 to $50{ }^{\circ} \mathrm{C}$ significantly lowers deposition rates as well as roughness. BHA content in the coatings has shown an increase in hardness values. Other plating parameters such as temperature, $\mathrm{pH}$ and current density have also been observed to have a significant effect on volume fraction of BHA in the film. By controlling the plating parameters a maximum of $\sim 20 \%$ particulate could be incorporated in the Ni matrix at rates approaching $\sim 1 \mu \mathrm{m} / \mathrm{min}$.

\section{Acknowledgements}

Defence Research and Development Organization is acknowledged for financial assistance, Prof. Satish Kailash, Department of Mechanical Engineering, Indian Institute of Science, Bangalore, for providing Optical Profilometer facility and Mr Bhaskar Mukri, Solid State and Structural Chemistry Unit, Indian Institute of Science, Bangalore, for helping in combustion synthesis experiments.

\section{References}

Aoudi S M, Paudel Y, Simonson W J, Kohli Q G, Muratore C and Voevodin A A 2009 Surf. Coat. Technol. 2031304

Allam I M 1991 J. Mater. Sci. 263977

Borkar T and Harimkar S P 2011 Surf. Coat. Technol. 2054124

Burzynska L, Rudnik E, Koza J, Blaz L and Szymanski W 2008 Surf. Coat. Technol. 2022545

Baker C C, Chromik R R, Wahl K J, Hu J J and Voevodin A A 2007 Thin Solid Films $\mathbf{5 1 5} 6737$

Chang Y and Lee L 1988 Mater. Chem. Phys. 20309

Chaparro A, Arnulfo W and Vera L E 2007 Revista Matéria 12583

Choua M, Ger M, Ke S, Huangc Y and Wu S 2005 Mater. Chem. Phys. 92146

Corte C D and Sliney H E 1990 Powder Metall. Compos. (NASATM-102355)

Das N A and Patil K C 1994 Ceram. Int. 2057

Davies T J, Emblem H G, Biedermann M, Chen W and Douri W A 1998 J. Mater. Sci. Lett. 211845

Donnet C and Erdemir A 2004 Surf. Coat. Technol. 180-181 76

Debsikdar J C 1989 J. Mater. Sci. 243565

El-Sherik A M, Erb U and Page J 1996 Surf. Coat. Technol. 8870

Gupta S, Filimonov D, Palanisamy T, El-Raghy T and Barsoum M W 2007 Wear 2621479

Guglielmi N 1972 J. Electrochem. Soc: Electrochem. Sci. Technol. 1191009

Hamid Z A and Ghayad I M 2002 Mater. Lett. 53238

Hou K H, Ger M D, Wang L M and Ke S T 2002 Wear 253994

Kirchhoff M, Specht U and Veser G 2005 Nanotechnology 16 S401

Lee H K, Lee H Y and Jeon J M 2007 Surf. Coat. Technol. 2014711

Lele M B, Seshadri S K and Ramesh C S 1989 Proceedings of the annual technical meeting (Calcutta: Indian Institute of Metals) 50

Machida M, Eguchi K and Arai H 1988 Bull. Chem. Soc. Jpn 61 3659

Miyoshi K 2007 NASA-TM-214668

Muller C, Sarret M and Benballa M 2002 Surf. Coat. Technol. 162 49 
Parida G, Chaira D, Chopkar M and Basu A 2011 Surf. Coat. Technol. 2054871

Pompei E, Magagnin L, Lecis N and Cavallotti P L 2009 Electrochim. Acta $\mathbf{5 4} 2571$

Qu N S, Zhu D, Chan K C and Lei W N 2003 Surf. Coat. Technol. 168123

Ramesh C S, Seshadri S K and Iyer K J L 1991a Indian J. Technol. 29179

Ramesh C S, Seshadri S K and Iyer K J L 1991b Wear 145189

Ramesh C S, Seshadri S K and Iyer K J L 1991c Wear 156205

Ramesh C S, Seshadri S K and Iyer K J L 1991d Ceramic Trans. Adv. Compos. Mater. 19885

Rethinam A J, Ramesh Bapu G N K and Krishnan R M 2004 Mater. Chem. Phys. 85251

Sohrabia A, Dolatib A, Ghorbania M, Monfared A and Stroevec P 2010 Mater. Chem. Phys. 121497

Sun X J and Li J G 2007 Tribol. Lett. 28223
Shi L, Sun C, Gao P, Zhou F and Liu W 2006 Appl. Surf. Sci. 252 3591

Surender M, Balasubramaniam R and Basu B 2004 Surf. Coat. Technol. 18793

The measurement of Zeta potential Using an Autotitrator: Effect of $\mathrm{pH}$, Application Note by Malvern Instruments 2005

Utsonomiya A, Tanaka K, Morikawa H, Marumo F and Kojima H 1988 J. Solid State Chem. 75197

Voevodin A A and Zabinski J S 2005 Compos. Sci. Technol. 65741

Wang S C and Cheng W C J 2003 Mater. Chem. Phys. 78574

Wang W, Hou F Y, Wang H and Guo H T 2005 Scr. Mater. 53613

Webb P R and Roberstson N L 1994 J. Electrochem. Soc. 141669

Xia Y, Sasaki S, Murakami T, Nakano M, Sh Li and Wang H 2007 Wear 262765

Xia Y, Wang L, Liu X and Qiao Y 2008 Tribol. Lett. 30151

Zoikis-Karathanasis A, Pavlatou E A and Spyrellis N 2010 J. Alloys Compd 494396 